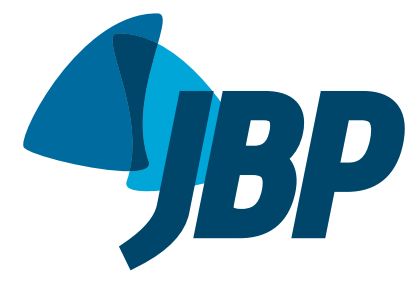

\title{
Effects of emissions from sugar cane burning on the trachea and lungs of Wistar rats
}

\author{
Verena Sampaio Barbosa Matos¹, Felipe da Silva Gomes², \\ Tarcio Macena Oliveira² ${ }^{2}$ Renata da Silva Schulz ${ }^{1}$, Lídia Cristina Villela Ribeiro ${ }^{3}$, \\ Astria Dias Ferrão Gonzales ${ }^{3,4}$, Januário Mourão Lima ${ }^{4}$, \\ Marcos Lázaro da Silva Guerreiro,
}

1. Centro Universitário Jorge Amado Unijorge - Salvador (BA) Brasil.

2. Faculdade Regional da Bahia, Salvador (BA) Brasil.

3. Universidade do Estado da Bahia UNEB - Salvador (BA) Brasil.

4. Programa de Mestrado Profissional em Bioenergia, Faculdade de Tecnologia e Ciências da Bahia, Salvador (BA) Brasil.

Submitted: 12 September 2016. Accepted: 5 January 2017

Study carried out at the Faculdade de Tecnologia e Ciências da Bahia, Salvador (BA) Brasil.

\begin{abstract}
Objective: To evaluate the effects of exposure to emissions from sugar cane burning on inflammatory mechanisms in tissues of the trachea and lung parenchyma in Wistar rats after different periods of exposure. Methods: This was an experimental open randomized study. The animals were divided into four groups: a control group (CG) underwent standard laboratory conditions, and three experimental groups were exposed to emissions from sugar cane burning over different periods of time, in days-1 (EG1), 7 (EG7), and 21 (EG21). After euthanasia with $200 \mathrm{mg} / \mathrm{kg}$ of ketamine/xylazine, fragments of trachea and lung were collected and fixed in $10 \%$ formalin. Histological analyses were performed with H\&E and picrosirius red staining. Results: No inflammatory infiltrates were found in the tissues of CG rats. The histological examination of tissues of the trachea and lung parenchyma revealed that the inflammatory process was significantly more intense in $E G 7$ than in the $C G$ ( $p<0.05$ and $p<0.01$, respectively). In comparison with the $C G$ and EG1, angiogenesis in the lung parenchyma and collagen deposition in tracheal tissues were significantly greater only in EG21 ( $p<0.001$ and $p<0.01$, respectively). Conclusions: In this sample, emissions from sugar cane burning induced acute focal and diffuse inflammation in the lamina propria of tracheal tissues, with no loss of ciliated epithelial tissue. In the lung parenchyma of the animals in the experimental groups, there was interstitial and alveolar edema, together with polymorphonuclear cell infiltrates.
\end{abstract}

Keywords: Saccharum; Smoke; Inflammation; Respiratory system.

\section{INTRODUCTION}

Sugar cane, Saccharum officinarum, is widely cultivated in Brazil for the production of ethanol and sugar, being essential to the country's economy. ${ }^{(1,2)}$ Harvesting of sugar cane, when performed manually, is preceded by burning of sugar cane fields to remove dry leaves, facilitate cutting, and reduce the risk of bites and stings by venomous animals. ${ }^{(3-7)}$

Sugar cane combustion releases a large quantity of particulate matter (PM), in addition to gases, such as ozone, carbon monoxide, nitric oxide, sulfur oxide, formaldehyde, benzopyrene, and polycyclic aromatic hydrocarbons, ${ }^{(6-8)}$ all of which contribute to air pollution and adversely affect human health. . $^{(2,9,10)}$

The PM and toxic compounds generated by sugar cane burning are harmful to the respiratory tract, because as they are inhaled and deposited in the lower airways, they are phagocytosed by alveolar macrophages, which release cytotoxic cytokines, thus inducing inflammation. ${ }^{(4,8)}$ The stress caused by smoke can trigger a series of cellular reactions that aim to restore stability; however, when this stress is chronic, it causes irreversible cellular damage.(11) Coarse PM from smoke damages the upper airways, which are directly exposed to the external environment, whereas fine PM from smoke accumulates in the bronchi and bronchioles, leading to permanent damage and fibrosis. ${ }^{(12,13)}$ Alveolar structures are susceptible to responses of an inflammatory nature and can cause pathological reactions with obstructive and restrictive consequences, ${ }^{(11,12,14-16)}$ generally associated with the process of tissue remodeling. ${ }^{(14)}$

Although the risks from exposure to smoke, such as tobacco smoke or emissions from fossil fuel burning, are known, there have been few studies on this topic. Therefore, the objective of the present investigation was to use an experimental model to evaluate the effects of exposure to emissions from sugar cane burning on inflammatory mechanisms in tissues of the trachea and lung parenchyma after different periods of exposure.

\section{METHODS}

This was an experimental open randomized study. In the study, 28 male Wistar rats weighing 250-300 g were housed in cages with sawdust bedding, maintained on a $12 / 12$-h light/dark cycle at $25-28^{\circ} \mathrm{C}$, and provided free access to standard rodent chow and filtered water. The animals were divided into four groups: a control group (CG) of 4 animals underwent standard laboratory 
conditions for $24 \mathrm{~h}$; and three experimental groups of 8 animals each were exposed to emissions from sugar cane straw burning for consecutive periods of 1,7 , and 21 days (EG1, EG7, and EG21, respectively). For the purposes of the study, a combustion chamber with a portable air extraction device was built where $200 \mathrm{~g}$ of sugar cane straw were burnt, generating a continuous stream of smoke that was piped into the cages of the experimental animals for $2 \mathrm{~h}$ daily at the same time of day (Figure 1 ).

The animals were euthanized by i.p. administration of $5 \%$ ketamine/xylazine diluted with $2 \mathrm{~mL}$ of physiological saline. After this procedure, the trachea was exposed and cannulated, a laparotomy was performed to separate the organs, and the abdominal aorta and inferior vena cava were sectioned. The trachea was then occluded by suture to maintain the lungs at functional residual capacity. A trans-sternal thoracotomy was performed through the diaphragm to remove the trachea and lungs. The collected organs were washed with physiological saline for macroscopic examination and were fixed in $10 \%$ buffered formalin.

Tissue fragments obtained from the material were processed conventionally and embedded in paraffin to prepare slides containing $5-\mu \mathrm{m}$ sections. The sections were stained with $\mathrm{H} \& \mathrm{E}$ and picrosirius red for analysis under light microscopy (BX51; Olympus Optical, Tokyo, Japan) at a magnification of $\times 100$. A digital camera (C-7070; Olympus) was used to obtain photomicrographs. To perform a semi-quantitative microscopic analysis, the histological changes found were classified as mild, moderate, or marked.

For a morphometric analysis, three photomicrographs were obtained of non-overlapping fields of the tissues studied. In the tracheal sections, areas containing hyaline cartilage, lamina propria, and ciliated epithelium were selected. In the lung parenchyma, bronchioles, alveoli, and blood vessels were evaluated. The nuclear area was quantified (in pixels) to evaluate the inflammatory process, using Adobe Photoshop CS5 software (Adobe Systems Inc.; San Jose, CA, USA). Collagen deposition was quantified by picrosirius red staining, positive staining corresponding to the presence

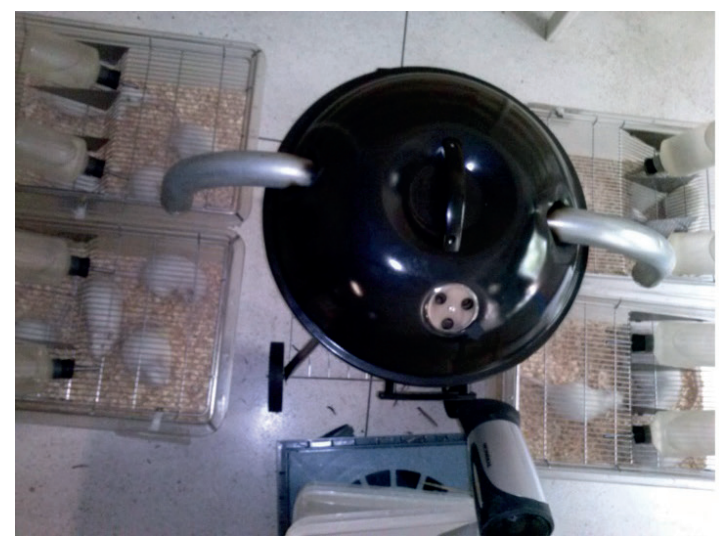

of type I collagen. Angiogenesis was assessed by counting the number of blood vessels per quadrant of each panoramic photomicrograph, using BioEstat 5.3 software.

A statistical analysis was carried out using the ShapiroWilk normality test. After confirmation of normality, ANOVA with Tukey's post hoc test was used. In cases of non-normality, the Kruskal-Wallis test and Dunn's post hoc test were used. Results were expressed as group means and standard deviations and as box plots. The level of significance was set at $5 \%$.

The study was approved by the Animal Research Ethics Committee of the Faculdade Adventista da Bahia (Protocol no. 013/2014).

\section{RESULTS}

Macroscopic examination of the trachea revealed no changes in tissue color or integrity in any of the groups. The lungs of EG7 and EG21 rats showed focal and diffuse macroscopic changes in different lobes, these changes being related to tissue color and texture.

The histological findings for each group are described below.

In the CG, there were no inflammatory infiltrates or structural tissue changes in the trachea (Figure 2). The lung parenchyma showed no alveolar, septal, or bronchiolar changes and was of normal appearance (Figure 3).

In EG1, a mild inflammatory infiltrate was present in the trachea in $87.5 \%$ of the cases. However, in $12.5 \%$ of the samples analyzed, the inflammatory response was intense and predominantly focal (Figure 2). In the lung parenchyma, an inflammatory process, consisting of $50 \%$ of polymorphonuclear cells, was present in $75 \%$ of the cases, and the diffuse form predominated over the focal one. Infiltrates were found in perivascular areas (ranging from mild to moderate) and in peribronchiolar areas. In addition, mild interstitial edema was observed, and there was no collagen deposition (Figure 3 ).

In EG7, inflammatory infiltrates of varying intensitymild (in $62.5 \%$ of the cases), moderate (in $50.0 \%$ ),

Figure 1. Photograph (in A) and schematic (in B) of the combustion chamber. 


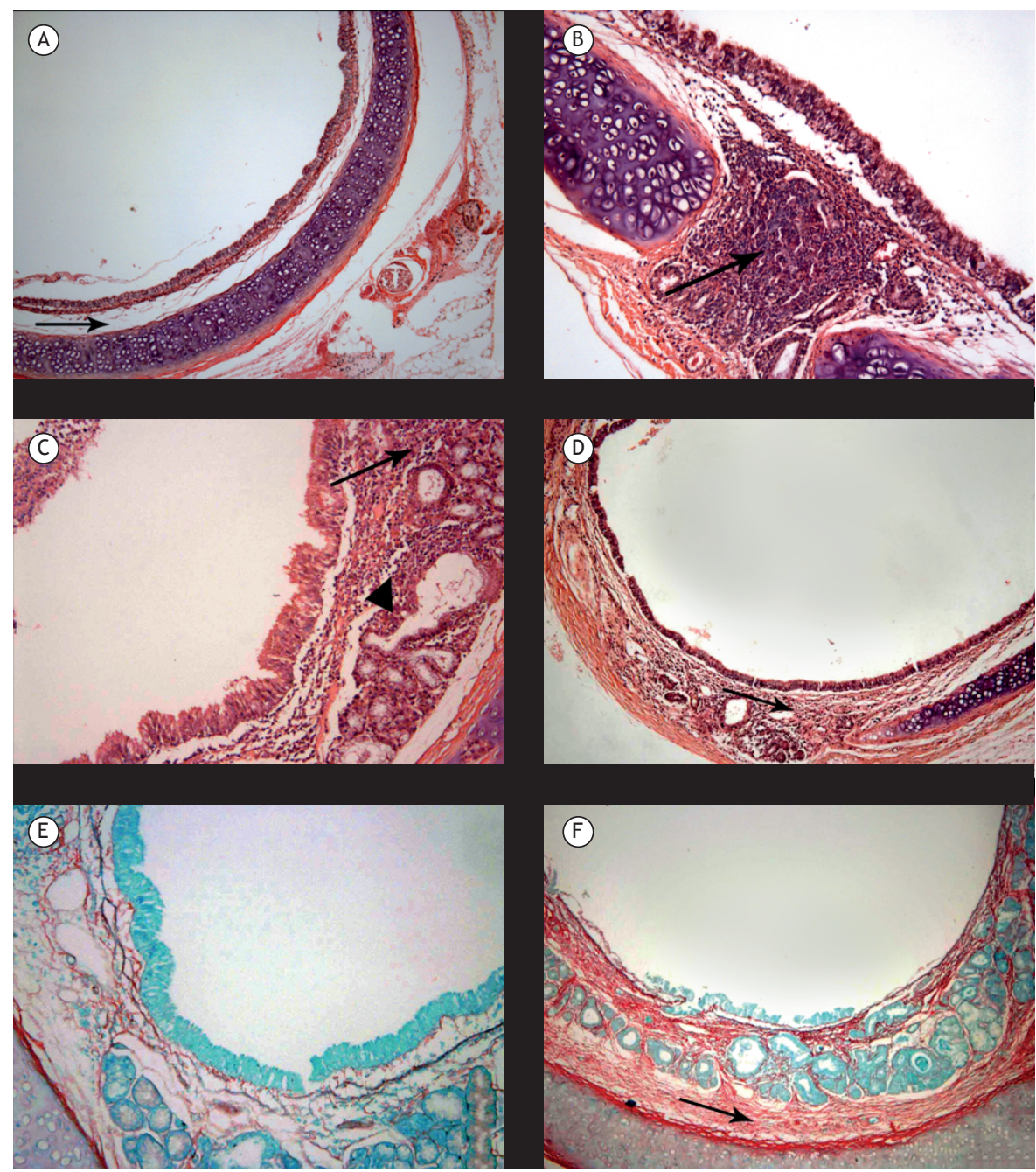

Figure 2. Photomicrographs of tracheal sections from animals in the different groups studied (H\&E and picrosirius red; magnification, $\times 100)$. A (control group), Photomicrograph showing hyaline cartilage of normal appearance, with preservation of ciliated epithelium and no inflammatory infiltrates in the lamina propria (arrow). B (group exposed to emissions from sugar cane straw burning for 1 day), Photomicrograph showing intense focal inflammatory infiltrate in the lamina propria (arrow). C (7-day exposure group), Photomicrograph showing moderate diffuse acute inflammatory infiltrate in the lamina propria of the mucosa (arrow) and in the submucosal region adjacent to the seromucous glands (triangle), with ciliary preservation. D (21 day-exposure group), Photomicrograph showing mild to moderate diffuse inflammatory infiltrate in the lamina propria of the mucosa (arrow). E (7-day exposure group), Photomicrograph showing mild staining for collagen. F (21-day exposure group), Photomicrograph showing increased acidophilia of the connective tissue, indicating collagen deposition (arrow).

and intense (in 25.0\%)-were present in the tracheal tissue (Figure 2). The onset of collagen deposition was demonstrated by the increased acidophilic reaction in the trachea after picrosirius red staining (Figure 2). Microscopic examination of the lung parenchyma revealed an inflammatory process in $87.5 \%$ of the cases and a polymorphonuclear cell infiltrate in $62.5 \%$. A mild to intense diffuse inflammatory process was present in $75 \%$ of the cases. A perivascular infiltrate pattern was present in $62.5 \%$ of the specimens. In addition, perivascular and peribronchiolar collagen deposition was found (Figure 3).

In EG21, a diffuse inflammatory infiltrate was observed in $75 \%$ of the cases, being of mild (in $25 \%$ ) to moderate (in 50\%) intensity. No intense inflammatory infiltrates were found (Figure 2). After picrosirius red staining, there was increased acidophilia, indicating the presence of collagen (Figure 2). Histological examination of the lung parenchyma revealed mild to intense diffuse inflammatory infiltrates, with a predominance of mononuclear cells, in $100 \%$ of the cases. There was mild perivascular and peribronchiolar inflammation in $50 \%$ and $25 \%$ of the cases, respectively. Necrosis was observed in $37.5 \%$ of the cases and angiogenesis was observed in $100 \%$ ( $p<0.001$ ) when EG21 was compared with the CG and EG1; in addition, perivascular and peribronchiolar collagen deposition was seen, as was alveolar collagen deposition (Figure 3). 


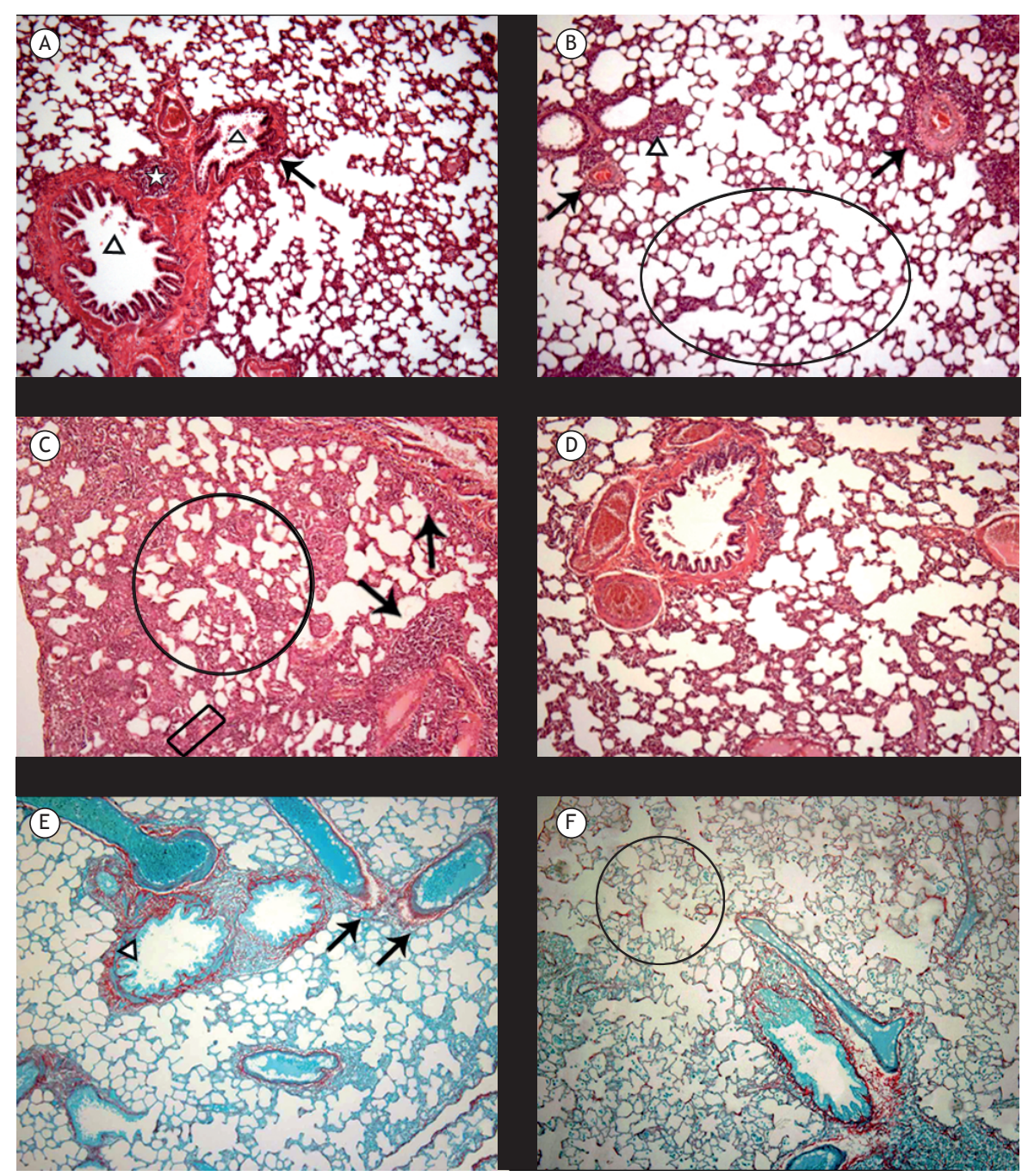

Figure 3. Photomicrographs of tissue sections from animals in the different groups studied (H\&E and picrosirius red; magnification, $\times 100)$. A (control group), Photomicrograph showing terminal bronchioles (triangle), respiratory bronchioles (arrow), alveolar ducts, and bronchus-associated lymphoid tissue (star) without tissue changes. B (group exposed to emissions from sugar cane straw burning for 1 day), Photomicrograph showing focal perivascular (arrows) and peribronchiolar (triangle) inflammatory infiltrates and diffuse infiltrate in the lung parenchyma (circle). C (7-day exposure group), Photomicrograph showing changes in alveolar architecture (circle) and intense, diffuse peribronchiolar and perivascular inflammatory infiltrates (arrows). D (21-day exposure group), Photomicrograph showing moderate diffuse alveolar inflammatory infiltrate, together with alveolar edema and septal losses. E (7-day exposure group), Photomicrograph showing perivascular (arrows) and peribronchiolar (triangle) collagen deposition. $\mathrm{F}$ (21-day exposure group), Photomicrograph showing perivascular and peribronchiolar collagen deposition and alveolar collagen deposition (circle).

Morphometric and statistical analysis (Figure 4) demonstrated the presence of an inflammatory process in the tracheal tissue of experimental group rats. The mean nuclear area (in pixels) was $379.78 \pm 105.65$ in the CG, $650.36 \pm 147.74$ in EG1, 899.18 \pm 183.65 in $E G 7$, and $751.96 \pm 143.64$ in EG21. In comparison with the CG, EG7 showed a more significant inflammatory response $(p<0.05)$. The data obtained from the morphometric analysis are complementary to the findings of the semi-quantitative analysis.

Morphometry after picrosirius red staining revealed no collagen deposition in the CG and showed a slight progressive, but not statistically significant, increase in acidophilia in EG1 and EG7. However, tracheal tissue collagen deposition was found to be greater in EG21 than in the CG and EG1 ( $p<0.01$ for both; Figure 4).

Morphometric analysis of the lung parenchyma was performed by determining the mean nuclear area (in pixels). In the CG, the mean nuclear area was $893.13 \pm 51.89$, which is within normal values. In EG1, polymorphonuclear and mononuclear cellularity started to increase, and the mean nuclear area was $1,373.66 \pm 155.43$; in EG7, the mean nuclear area reached $2,280.98 \pm 744.80(p<0.01$ in the intergroup comparison). However, the mean nuclear area decreased 
to $1,251.31 \pm 231.75$ in EG21, which is suggestive of tissue repair (Figure 5 ).

Morphometric analysis showed no angiogenesis in the CG, EG1, or EG7. In contrast, in EG21, angiogenesis was detected in $100 \%$ of the cases (Figure 5).

\section{DISCUSSION}

Our results show that exposure of Wistar rats to emissions from sugar cane burning over different periods of exposure was associated with increased inflammation in tracheal and lung tissues. Focal and diffuse inflammatory polymorphonuclear cell infiltrates were found in the acute phase in the trachea of experimental group rats, especially of EG7 rats. No loss of ciliated epithelium was observed in any of the

(A)

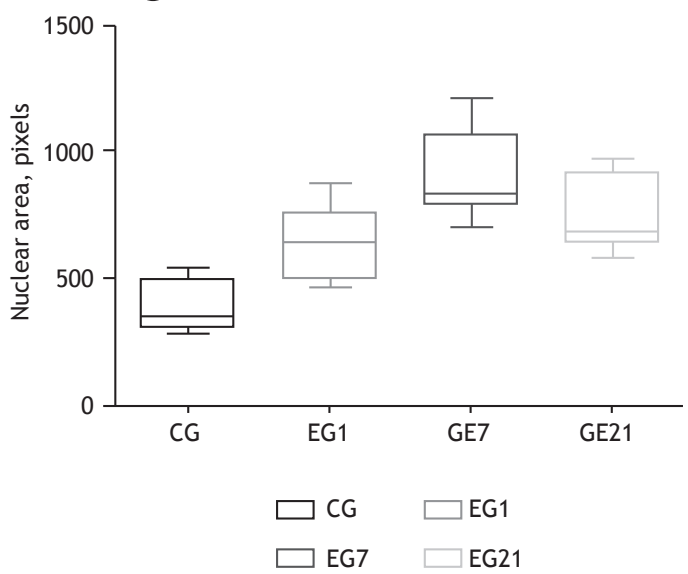

experimental groups relative to the CG. Tissue fibrosis in the trachea, corresponding to the early stages of the chronic phase, was confirmed in EG21. In the lung parenchyma, alveolar, vascular, and bronchiolar changes were observed in the experimental groups relative to the CG. The time criteria adopted for designating the inflammatory response phases were based on a study of Wistar rats that were administered bleomycin sulfate, in which the inflammatory response was characterized as acute (from day 1 to day 7 after the insult); subacute (from day 7 to day 14 after the insult); and resolving (from day 15 to day 30 after the insult). ${ }^{(17)}$

An experimental study, in which rats received intratracheally-instilled fine PM, observed lung inflammation characterized by macrophage and

(B)

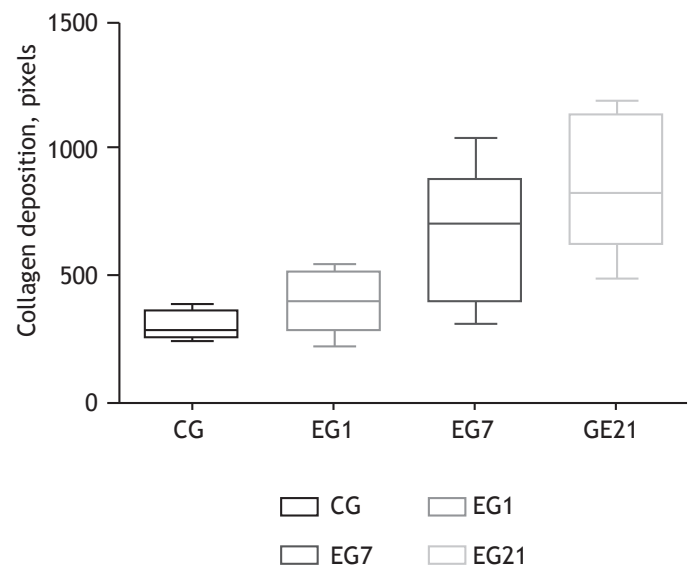

Figure 4. Morphometric analysis of the trachea in the control group (CG) and in the groups exposed to emissions from sugar cane straw burning for 1 day (EG1), for 7 days (EG7), and for 21 days (EG21). In A, kinetics of the inflammatory process as determined by nuclear area analysis. EG7 showed a significant difference relative to the CG $(p<0.05)$. There was a reduction in inflammation in EG21, suggestive of initiation of tissue repair. In B, determination of collagen deposition. Only EG21 showed significant differences relative to the CG and EG1 ( $p<0.01$ for both).

(A)

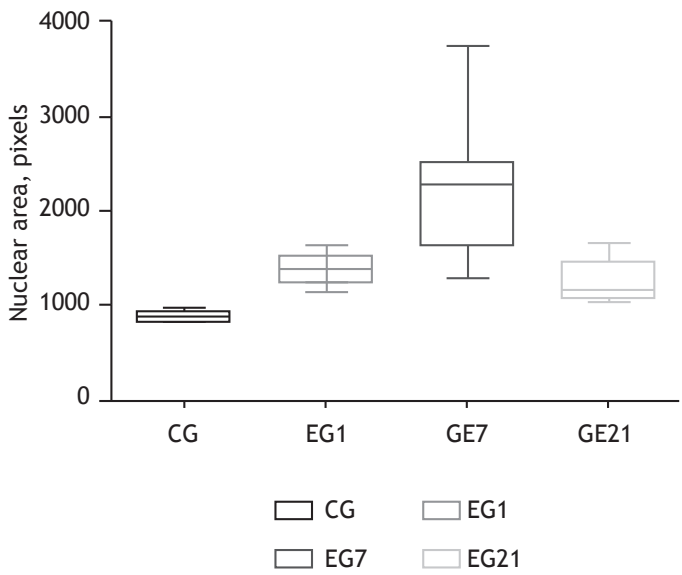

(B)

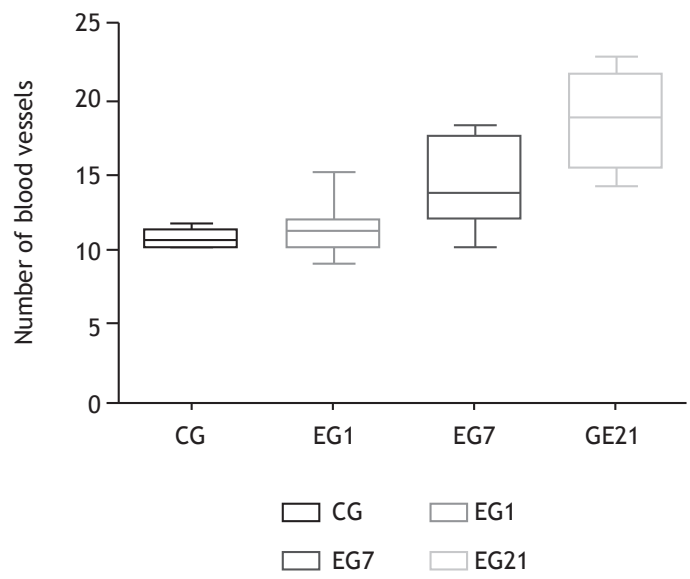

Figure 5. Morphometric analysis of the lung parenchyma in the control group (CG) and in the groups exposed to emissions from sugar cane straw burning for 1 day (EG1), for 7 days (EG7), and for 21 days (EG21). In A, nuclear area analysis showing the presence of an inflammatory infiltrate in all groups. EG7 showed statistically significant differences relative to the CG, EG1, and EG21 ( $p<0.01$ for all). There was a reduction in inflammation in EG21, suggestive of initiation of tissue repair. In $B$, quantification of the number of blood vessels. There was an increase in EG7, but angiogenesis was confirmed only in EG21 with significant differences relative to the CG and EG1 ( $p<0.001$ for both). 
neutrophil infiltrates, demonstrating that cytokines (IL-12 and IFN- $y$ ) play a key role in injury severity ${ }^{(18)}$; similarly, an experimental rabbit study found an increased recruitment of macrophages and polymorphonuclear cells in the lung parenchyma. ${ }^{(19)}$ In the present study, we found inflammatory changes consisting of polymorphonuclear cells and alveolar macrophages in the lung tissue of rats as early as in EG1.

Tracheal instillation of low doses of PM from sugar cane burning produced changes in the respiratory tract by reducing the thickening of the connective tissue and increasing the production of proinflammatory cytokines and chemokines. ${ }^{(8)}$ In the present study, morphometry confirmed that emissions from sugar cane burning are able to induce significant and progressive necrotic inflammatory processes, even after short periods of exposure. Alveolar macrophages (after phagocytosis), as well as lung epithelial cells, respond to exposure to PM by increasing inflammatory mediator production, which can lead to certain mechanisms, such as leukocyte proliferation and activation, apoptosis, and endothelial repair. ${ }^{(20)}$ These changes are explained by the elements present in smoke; these data confirm our findings, especially in EG7.

It is known that the size of particles emitted from biomass burning has a negative impact on the airways. ${ }^{(21,22)}$ The size of inhaled PM, in terms of varying particle granularity, determines the clinical manifestations in the body. Coarse $\mathrm{PM}(<10 \mu \mathrm{m})$ is retained in the upper airways and can be removed by ciliary activity; thin PM $(<2.5 \mu \mathrm{m})$ and ultrafine particles/nanoparticles $(<0.1 \mu \mathrm{m})$ are usually the result of incomplete oxidation of carbon. ${ }^{(22-24)}$ Fine and ultrafine PM have the ability to reach the alveoli and be phagocytosed by alveolar macrophages, having greater deleterious effects, such as changes in lung mechanics, alveolar collapse, and oxidative stress, in rats. ${ }^{(23-26)}$ Chronic exposure to fine particles is strongly associated with higher rates of chronic respiratory disease. ${ }^{(3)}$

After direct exposure of mice to dung biomass smoke for 7 consecutive days, a significant increase in cellularity, especially in macrophage cellularity, was observed in the lungs. ${ }^{(27)}$ Exposure to emissions from sugar cane burning produced inflammatory infiltrates of varying intensity in the animals of the present study, and, in EG7, there was a more significant inflammatory infiltrate in both tissues of the trachea and lung parenchyma, given that there were areas of more severe inflammation.
Damage to the lung parenchyma after chronic exposure to dung biomass smoke and cigarette smoke includes moderate to marked interstitial inflammation, bronchial and perivascular inflammation, vascular congestion, alveolar destruction, an increase in the number of macrophages, and an increase in vascular wall thickness. ${ }^{(3)}$ In the present study, although the exposure was acute only, it was possible to observe that the experimental groups showed a growing change in alveolar structure (septal loss) relative to the CG, with PM being phagocytosed especially in EG1. Areas suggestive of necrosis were identified especially in EG7 and EG21, and angiogenesis was confirmed in EG21.

Rabbits chronically exposed to emissions from biomass and cigarette burning show perivascular inflammation, peribronchiolar inflammation, parenchymal infiltrate, and fibrosis, with respiratory epithelial proliferation and emphysematous changes. ${ }^{(28)}$ Using picrosirius red staining, we demonstrated that, in EG7 and EG21, there were areas of tracheal tissue collagen deposition, areas of peribronchiolar and vascular collagen deposition, and diffuse areas of lung parenchymal collagen deposition, which suggest that continued exposure can lead to a tissue fibrotic process.

On the basis of morphological criteria, we found that the changes in alveolar structure in EG7 and the rupture of interalveolar septa in EG21 were consistent with the findings of a rat study that showed that $24.6 \%$ of the cigarette smoke-exposed animals had increased alveolar spaces relative to controls, which were not exposed. ${ }^{(29)}$

Therefore, the above data allow us to state that acute exposure to emissions from sugar cane burning is able to induce severe damage to the respiratory system. The components of emissions from sugar cane burning trigger polymorphonuclear cell inflammatory processes in the trachea and also induce inflammatory infiltrates and interstitial and alveolar edema in the lung parenchyma of Wistar rats. Changes in alveolar architecture and angiogenesis are also found.

Further research targeting prolonged exposure and determination of proinflammatory marker levels is needed to demonstrate the potential damage caused by chronic exposure to the components of emissions from sugar cane burning, since workers in sugar cane fields and the neighboring population are exposed to these emissions for long periods of their life.

\section{REFERENCES}

1. Brasil. Ministério da Agricultura, Pecuária e Abastecimento. Anuário Estatístico da Agroenergia 2014. Brasília: o Ministério; 2015.

2. Lelieveld J. Evans JS, Fnais M, Giannadaki D, Pozzer A. The contribution of outdoor air pollution sources to premature mortality on a global scale. Nature. 2015;525(7569):367-71. https://doi. org/10.1038/nature15371

3. Dogan OT, Elagoz S, Ozsahin SL, Epozturk K, Tuncer E, Akkurt I. Pulmonary toxicity of chronic exposure to tobacco and biomass smoke in rats. Clinics (Sao Paulo). 2011;66(6):1081-7. https://doi. org/10.1590/S1807-59322011000600027

4. Ribeiro H. Sugar cane burning in Brazil: respiratory health effects [Article in Portuguese]. Rev Saude Publica. 2008;42(2):370-6. https://

\section{doi.org/10.1590/S0034-89102008005000009}

5. Brasil. Ministério da Agricultura, Pecuária e Abastecimento [homepage on the Internet]. Brasília: o Ministério [cited 2016 Feb 10]. Sapcana - Sistema de Acompanhamento de Produção Canavieira. [Adobe Acrobat document, 3p.]. Available from: http://www.agricultura. gov.br/assuntos/sustentabilidade/agroenergia/acompanhamento-daproducao-sucroalcooleira/arquivos-2014-2015/16-04-2014.pdf/view

6. The WHO Pages. Wildland/Negetation Fires. Ann Burns Fire Disasters [serial on the Internet]. 2000 [cited 2016 Feb 10] 13(3):178 [about 6 p.]. Available from: www.medbc.com/annals/review/vol_13/ num_3/text/vol13n3p178.htm

7. Ribeiro H, Ficarelli TR. Queimadas nos canaviais e perspectivas 
dos cortadores de cana-de-açúcar em Macatuba, São Paulo Saude Soc. 2010;9(1)48-63. http://dx.doi.org/10.1590/ S0104-12902010000100005 https://doi.org/10.1590/S0104 12902010000100005

8. Bittar OT. Estudo dos efeitos do material particulado proveniente da biomassa de cana-de-açúcar sobre o aparelho respiratório $e$ circulatório de ratos Wistar combinados ou não com a infecção estafilocócica [thesis]. Campinas: Universidade Estadual de Campinas; 2013.

9. Hutton G. The economics of health and climate change: key evidence for decision making. Global Health. 2011;7:18. https://doi. org/10.1186/1744-8603-7-18

10. National Aeronautics and Space Administration [homepage on the Internet]. Washington, DC: the Administration; c2015 lupdated 2015 Jul 30; cited 2016 Feb 10]. A Story of Ozone: The Earth's natural sunscreen. Available from: https://www.nasa.gov/content/goddard/ a-story-of-ozone-earths-natural-sunscreen

11. Prado GF, Zanetta DM, Arbex MA, Braga AL, Pereira LA, de Marchi $M R$, et al. Burnt sugarcane harvesting: Particulate matter exposure and the effects on lung function, oxidative stress, and urinary 1-hydroxypyrene. Sci Total Environ. 2012;437:200-8. https://doi. org/10.1016/.s.sitotenv.2012.07.069

12. Arbex MA Santos Ude $P$, Martins LC, Saldiva PH, Pereira $L A$, Braga AL. Air pollution and the respiratory system. J Bras Pneumol. 2012;38(5):643-55. https://doi.org/10.1590/S180637132012000500015

13. Mazzole-Rocha F, Carvalho GM, Lanzetti M, Valença SS, Silva LF, Saldiva PH et al. Respiratory toxicity of repeated exposure to particles produced by traffic and sugar cane burning. Respir Physiol Neurobiol. 2014;191:106-13. https://doi.org/10.1016/j.resp.2013.11.004

14. William AH, Wallace A. Simpson J, Hirani N. Acute lung injury. In: Hasleton P, Flieder DB, editors. Spencer's Pathology of the Lung. 6th ed. Cambridge: Cambridge University Press; 2013.p. 342-60.

15. Paraiso ML, Gouveia N. Health risks due to pre-harvesting sugarcane burning in São Paulo State, Brazil. Rev Bras Epidemiol. 2015;18(3):691701. https://doi.org/10.1590/1980-5497201500030014

16. Silva R, Oyarzún M, Olloquequi J. Pathogenic mechanisms in chronic obstructive pulmonary disease due to biomass smoke exposure. Arch Bronconeumol. 2015;51(6)285-92. https://doi.org/10.1016/j. arbr.2015.04.013

17. Rossari JR. Fibrose pulmonar induzida por bleomicina intratraquea em ratos Wistar: uso do interferon- $\mathrm{a}-2 \mathrm{~b}$ em um modelo experimental de síndrome da distração respiratória aguda [dissertation]. Porto Alegre: Universidade Federal do Rio Grande do Sul; 2004.

18. Ding LR, Wang K, Fahmy B, Shen HH, Cormier S. Airborne fine particle matter induced pulmonary inflammation as well as oxidative stress in neonate rats. Chin Med J (Engl). 2010;123(20):2895-900.

19. Miyata R, Bai N, Vincent R, Sin DD, Van Eeden SF. Statins reduce ambient particulate matter-induced lung inflammation by promoting the clearance of particulate matter, $<10 \mu \mathrm{m}$ from lung tissues. Chest. 2013;143(2):452-60. https://doi.org/10.1378/chest.12-1237

20. Poma A, Limongi T, Pisan C, Granato V, Picozzi P. Genotoxicity induced by fine urban air particulate matter in the macrophages cell line RAW 264.7. Toxicol In Vitro. 2006;20(6):1023-9. https://doi. org/10.1016/j.tiv.2006.01.014

21. Bovo F, Wisniewski P. Efeitos de material particulado sobre mecanismos imunológicos. Biosaude. 2009;11(2):93-100.

22. Donaldson K, Stone V. Current hypotheses on the mechanisms of toxicity of ultrafine particles. Ann Ist Super Sanita. 2003;39(3):405-10.

23. Pope CA, Muhlestein JB, Anderson JL, Cannon JB, Hales NM, Meredith KG, et al Short-Term Exposure to Fine Particulate Matter Air Pollution Is Preferentially Associated With the Risk of ST-Segment Elevation Acute Coronary Events. J Am Heart Assoc. 2015;4(12). pii. e002506. https://doi.org/10.1161/JAHA.115.002506

24. Colombini MP. Exposição aguda ao material particulado total em suspensão proveniente de diferentes fontes e suas repercussões nas respostas inflamatórias, sistêmica e local, em ratos [thesis]. São Paulo. Faculdade de Medicina, Universidade de São Paulo; 2007.

25. Mazzoli-Rocha F, Magalhães CB, Malm O, Saldiva PH, Zin WA, Faffe DS. Comparative respiratory toxicity of particles produced by traffic and sugar cane burning. Environ Res. 2008;108(1):35-41. https://doi. org/10.1016/j.envres.2008.05.004

26. Riva DR, Magalhães CB, Lopes AA, Lanças T, Mauad T, Malm O, et al. Low dose of fine particulate matter (PM2.5) can induce acute oxidative stress, inflammation and pulmonary impairment in healthy mice. Inhal Toxicol. 2011;23(5):257-67. https://doi.org/10.3109/0895 8378.2011.566290

27. Mehra D, Geraghty PM, Hardigan AA, Foronjy R. A comparison of the inflammatory and proteolytic effects of dung biomass and cigarette smoke exposure in the lung. PLoS One. 2012;7(12):e52889. https:// doi.org/10.1371/journal.pone.0052889

28. Fidan F, Unlu M, Sezer M, Sahin O, Tokyol C, Esme H. Acute effects of environmental tobacco smoke and dried dung smoke on lung histopathology in rabbits. Pathology. 2006;38(1):53-7. https://doi. org/10.1080/00313020500459615

29. Zheng H, Liu Y, Huang T, Fang Z, Li G, He S. Development and characterization of a rat model of chronic obstructive pulmonary disease (COPD) induced by sidestream cigarette smoke. Toxicol Lett. 2009;189(3):225-34. https://doi.org/10.1016/|.toxlet.2009.06.850 